\title{
Histopathological Features of Dental Pulp Tissue from Bleached Mandibular Incisors
}

\author{
Douglas Augusto Roderjan ${ }^{1}$, Rodrigo Stanislawczuk ${ }^{1}$, Josimeri Hebling ${ }^{2}$, Carlos Alberto de Souza Costa ${ }^{3}$, Diana \\ Gabriela Soares ${ }^{3}$, Alessandra Reis ${ }^{1}$ and Alessandro Dourado Loguercio ${ }^{1}$ \\ 1. Department of Restorative Dentistry, School of Dentistry, State University of Ponta Grossa, Ponta Grossa/PR, Brazil \\ 2. Department of Orthodontics and Pediatric Dentistry, Araraquara School of Dentistry, Univ. Estadual Paulista, Araraquara/SP, \\ Brazil.
}

3. Department of Physiology and Pathology, Araraquara School of Dentistry, Univ. Estadual Paulista, Araraquara/SP, Brazil

Received: June 04, 2014 / Accepted: June 19, 2014 / Published: June 25, 2014.

\begin{abstract}
Mandibular incisors scheduled for extraction were subjected or not to three 15 -minute applications of a $35 \%$ hydrogen peroxide gel. Two days thereafter, bleaching effectiveness (according to a value-oriented shade guide) was evaluated, and histological analysis of pulp tissue was performed. Immediately and two days after bleaching, tooth sensitivity (TS) experience was recorded. Bleached teeth of both groups showed significant color improvement (Mann-Whitney; $p<0.05$ ). However, these teeth presented significant pulp alterations when compared with non-bleached teeth (Mann-Whitney; $p<0.05$ ), including areas of superficial necrosis associated with mild inflammatory reactions. These data were achieved by recordings of TS immediately after bleaching (Fisher's exact test; $\mathrm{p}<0.05$ ), which was reduced with time. Instead of 'no significant difference' being observed between young and old teeth (Mann-Whitney; $\mathrm{p}<0.05$ ), necrosis occurred in $60 \%$ of old bleached teeth in comparison with $100 \%$ of young teeth, associated with underlying tertiary dentin deposition. It was concluded that, regardless of the age of patients, the application of a $35 \%$-HP bleaching gel to mandibular incisors causes pulp damage, which was related to initial TS; however, superficial necrosis was more prevalent in young teeth.
\end{abstract}

Key words: Dental pulp, tooth bleaching, histological techniques.

\section{Introduction}

A common side-effect experienced by patients subjected to in-office bleaching therapy is tooth sensitivity (TS), which has been reported to affect up to $87 \%$ of patients in clinical trials [1-4]. Although this adverse effect is usually considered temporary and moderate, it can produce considerable discomfort to the patient [5]. A current study demonstrated that the degree of pulp damage caused by a bleaching gel with a high concentration of hydrogen peroxide (HP) depends on the thickness of enamel and dentin [6]. The authors reported the occurrence of necrosis in mandibular

Corresponding Author: Carlos Alberto de Souza Costa, professor, research fields: dental materials, cytotoxicity and biocompatibility. E-mail: casouzac@foar.unesp.br. incisor pulps treated with a $38 \%$-HP bleaching gel; however, only a mild inflammatory reaction was observed in the pulps of premolars. In recent clinical trials, the authors found the occurrence of tooth sensitivity (TS) in incisors, which was more prevalent in those teeth with thinner layers of enamel and dentin $[1,2]$. According to Camargo et al. [7], the thinner the hard dental structure, the more rapid is the inward enamel/dentin diffusion of HP to the pulp chamber.

It is known that the continuous deposition of secondary dentin, which occurs over time, both increases the thickness of dentin and decreases the diameters of dentinal tubules with age $[8,9]$. Both physiologic mechanisms decrease dentin permeability and may reduce the amount and the rate of HP 
diffusion across this tubular dental tissue to reach the pulp, likely reducing the tissue damage produced by such oxidizing products $[10,11]$. Whether thicker and less permeable dentin plays a protective role against the damage caused by HP in the pulp tissue is yet to be addressed. Therefore, the aim of this study was to evaluate the pulp responses of human mandibular incisors from young and old patients presenting for traditional in-office bleaching therapy.

\section{Experiments}

\subsection{Experimental Design}

Eighteen mandibular incisors, scheduled to be extracted for orthodontic or periodontal reasons, were selected for this study (Ethics Committee of Ponta Grossa University, SC, Brazil; \#09171/10) from patients who signed informed consent after description of the risks and benefits of participation in the study. The experiment was performed in accordance with the ethical standards of the Declaration of Helsinki, 1975, revised Hong Kong, 1989. Half of the incisors were obtained from young patients (age range, 18 to $30 \mathrm{yrs;}$ teeth extracted for orthodontic reasons) with the other half obtained from older participants (age equal to or higher than $54 \mathrm{yrs}$; teeth extracted for periodontal reasons). Each group of participants (young [YT] and old [OT]) was divided into two groups: Bleached (B) and Control ( $\mathrm{C}$ - non-bleached). The inclusion criteria were: initial enamel shade of A2 or darker (value-oriented shade guide; Vita Lumin, Vita Zahnfabrik, Bad Säckingen, Germany); positive response to $10 \mathrm{~s}$ of cold application (Endo-Frost, Roeko, Germany); absence of alterations in periapical radiographs; good general and oral health; and absence of reported TS. The exclusion criteria included: participants who had undergone tooth-bleaching procedures and presented anterior restorations; pregnant/lactating women; those with severe internal tooth discoloration (tetracycline stains, fluorosis, pulpless teeth); evidence of bruxism habits or any gross pathology in the mouth; and ongoing use of drug(s) with anti-inflammatory and antioxidant action.

\subsection{Clinical Procedures}

After prophylaxis, the gingival tissue of the teeth to be bleached was isolated with a light-cured gingival barrier (Top Dam, FGM, Joinville, SC, Brazil). A 35\%-HP gel (Whiteness HP Maxx, FGM) was applied according to the manufacturer's recommendation. After manipulation, a thin layer $(0.5 \mathrm{~mm})$ of gel was applied to the buccal tooth surface for $15 \mathrm{~min}$. This procedure was repeated two more times, totaling 45 min of tooth-bleaching. The tooth color was registered at baseline and two days after bleaching according to a value-oriented shade guide (Vita Lumin, Vita Zahnfabrik). The shade guide's 16 tabs were arranged from highest (B1) to lowest (C4) value $(\mathrm{B} 1 * \mathrm{~A} 1 * \mathrm{~B} 2 * \mathrm{D} 2 * \mathrm{~A} 2 * \mathrm{C} 1 * \mathrm{C} 2 * \mathrm{D} 4 * \mathrm{~A} 3 * \mathrm{D} 3 * \mathrm{~B} 3 * \mathrm{~A} 3.5 *$ $\mathrm{B} 4 * \mathrm{C} 3 * \mathrm{~A} 4 * \mathrm{C} 4)$. Although this scale is not linear in the truest sense, we treated the changes as representing a continuous and approximately linear ranking for the purpose of analysis. The change in the number of shade guide units $(\triangle \mathrm{SGU})$ was calculated as previously described [1-4]. Two days after the procedure, participants were asked if they had experienced any TS (yes/no) in the bleached tooth and, if yes, its duration. No attempt was made to record the TS intensity.

\subsection{Histological Evaluation}

Two days after the bleaching procedure, the teeth were extracted under local anesthesia. The roots were immediately sectioned midway between the cement/enamel junction (CEJ) by means of a high-speed hand-piece under water spray. The teeth were stored for $48 \mathrm{~h}$ in formalin fixative solution at $\mathrm{pH}$ 7.2, decalcified in buffered Morse's solution, dehydrated, vacuum-infiltrated with wax paraffin, and finally embedded in paraffin. Six-micrometer-thick serial sections were cut ("820" Spencer Microtome, Carson, CA, USA), mounted on glass slides, and stained with hematoxylin and eosin (H/E) and Masson's trichrome. All stained sections were 
evaluated under a light microscope (62774; Carl Zeiss, Oberköchen, Germany) operated by a calibrated examiner blinded to the groups. The histopathological events described in Table 1 were assessed and classified by a descriptive analysis.

\subsection{Dentin Thickness Measurement}

With the use of a light microscope (Diastar; Cambridge Instruments, Buffalo, NY, USA) adapted to a video camera (DXC-107A/107AP; Sony Electronics, Tokyo, Japan), 3 linear measures from the enamel/dentin junction to the pulp chamber were carried out to determine the dentin thickness (DT) of all sections of each tooth. The video images were loaded into a computer and processed with standard software (Mocha; Jondel Scientific, San Rafael, CA, USA). The readings from each tooth were averaged to obtain an average DT of each tooth [6].

\subsection{Statistical Analysis}

The $\triangle \mathrm{SGU}$ of the groups were calculated and compared with the non-parametric Kruskal-Wallis and Mann-Whitney U-test. The TS among groups was evaluated by Fisher's exact test. The data regarding the DT were analyzed by ANOVA and Tukey's test. For evaluation of the pulp responses, three established histopathological events were analyzed (Table 2). Thus, 3 scores per tooth were considered for statistical analysis. The overall comparison of the groups was performed with the non-parametric Kruskal-Wallis and Mann-Whitney tests. All tests were performed with appropriately computed critical values $(\alpha=0.05)$.

\section{Experimental Results}

The ages of the participants in the young group varied between 18 and 30 yrs old (mean, $20.1 \pm 4.3$ ), while participants in the old group were between 54 and $62 \mathrm{yrs}$ old (mean, $58.2 \pm 4.3$ ). The means/standard deviations and medians/interquartile ranges of $\Delta \mathrm{SGU}$ are shown in Table 3 . The $\Delta$ SGU was similar between teeth submitted to the bleaching protocol, regardless of the participant mean age. A higher $\Delta \mathrm{SGU}$ was observed in bleached (B) than in control $(C)$ groups $(p=0.001)$. A statistically higher TS was observed in B groups, regardless of participant age $(p=0.003$; Table 2). However, the participants reported that the TS decreased with time.

Concerning histological evaluation, the DT in C groups was measured from the enamel-dentin junction (EDJ) to the predentin. In experimental groups, the DT was measured from the EDJ to the calcium-traumatic

Table 1 Scores used during the histological examination: inflammatory cell response, tissue disorganization, and reactionary dentin formation.

\begin{tabular}{|c|c|}
\hline \multirow{2}{*}{ Score } & Inflammatory cell response \\
\hline & Characterization \\
\hline 0 & $\begin{array}{l}\text { None or a few scattered inflammatory cells present in the pulp area corresponding to the buccal surface of the tooth } \\
\text { to which the bleaching gel was applied }\end{array}$ \\
\hline 1 & Mild inflammatory cell infiltrate with polymorphonuclear or mononuclear leukocytes \\
\hline 2 & Moderate inflammatory cell infiltrate \\
\hline 3 & Severe inflammatory cell infiltrate \\
\hline \multirow{2}{*}{ Score } & Tissue disorganization \\
\hline & Characterization \\
\hline 0 & Normal pulp tissue \\
\hline 1 & $\begin{array}{l}\text { Pulp zones (odontoblast, acellular, and cell-rich) disorganization in the buccal surface of the tooth to which the } \\
\text { bleaching gel was applied }\end{array}$ \\
\hline 2 & Coronal pulp tissue disorganization with partial local necrosis \\
\hline 3 & Intense pulp disorganization with necrosis in the coronal and root pulp tissue \\
\hline \multirow{2}{*}{ Score } & Tertiary dentin formation \\
\hline & Characterization \\
\hline 0 & Absence \\
\hline 1 & Modest hard tissue deposition in coronal pulp of the tooth to which the bleaching gel was applied \\
\hline 2 & Moderate hard tissue deposition in the coronal pulp tissue of the tooth to which the bleaching gel was applied \\
\hline 3 & Intense hard-tissue deposition in the coronal and root pulp tissue \\
\hline
\end{tabular}


Table 2 Means \pm standard deviations (SD) and medians of shade guide units and $\Delta$ SGU for the experimental groups as well as the number of patients with tooth sensitivity (TS) for each group.

\begin{tabular}{|c|c|c|c|c|c|c|c|}
\hline \multirow[b]{3}{*}{ Groups } & \multicolumn{4}{|c|}{ Shade guide unit } & \multirow{2}{*}{$-\Delta \mathrm{SGU}(*)$} & \multirow{2}{*}{\multicolumn{2}{|c|}{ Sensitivity }} \\
\hline & & Before & & After & & & \\
\hline & Mean \pm SD & $\begin{array}{l}\text { Median } \\
\text { (interquartile range) }\end{array}$ & Mean \pm SD & $\begin{array}{l}\text { Median (interquartile } \\
\text { ranges) }\end{array}$ & Mean \pm SD & $\begin{array}{l}\text { Median } \\
\text { (interquartile } \\
\text { range) }\end{array}$ & $\begin{array}{l}\text { Total number of } \\
\text { patients/patients } \\
\text { with TS }(* *)\end{array}$ \\
\hline Control YT & $5.0 \pm 0.0$ & $5(5 / 5)$ & $5.0 \pm 0.0$ & $5(5 / 5)$ & $0.0 \pm 0.0$ & $0(0 / 0) \mathrm{A}$ & $0 / 0 \mathrm{a}$ \\
\hline Bleached YT & $5.5 \pm 1.4$ & $5(5 / 5)$ & $2.4 \pm 1.2$ & $2(2 / 5)$ & $1.0 \pm 1.2$ & $\begin{array}{l}1.0(0 / 3) \\
\text { A,B }\end{array}$ & $5 / 5 b$ \\
\hline Control OT & $5.0 \pm 0.0$ & $5(5 / 5)$ & $5.0 \pm 0.0$ & $5(5 / 5)$ & $0.0 \pm 0.0$ & $0(0 / 0) \mathrm{A}$ & $0 / 0 \mathrm{a}$ \\
\hline Bleached OT & $5.7 \pm 1.6$ & $5(5 / 5)$ & $3.5 \pm 1.3$ & $3(2 / 5)$ & $2.4 \pm 1.1$ & $3(3 / 3) B$ & $3 / 5 a, b$ \\
\hline
\end{tabular}

(*) Similar upper-case letters indicate statistically similar groups for $\Delta$ SGU (Mann-Whitney test, $\mathrm{p}<0.05)$. (**) Similar lower-case letters indicate statistically similar groups for tooth sensitivity (TS) (Fisher exact test, $\mathrm{p}<0.05$ ).

Table 3 Mean and standard deviation of dentin thickness $(\mu \mathrm{m})$ for each experimental group.

\begin{tabular}{lll}
\hline Experimental groups & Dentin thickness $(\mu \mathrm{m})^{*}$ & Main factor, age $(\mu \mathrm{m})$ \\
\hline Control YT & $1.77 \pm 0.07$ & $1.77 \pm 0.08 \mathrm{~b}$ \\
Bleached YT & $1.76 \pm 0.08$ & \\
Control OT & $1.98 \pm 0.11$ & $1.99 \pm 0.10 \mathrm{a}$ \\
Bleached YT & $1.99 \pm 0.09$ & \\
\hline
\end{tabular}

(*) Different letters indicate significant differences (ANOVA test, $\mathrm{p}<0.05$ ).

Table 4 Number of specimens for each group in each criterion as well as multiple comparisons among the experimental conditions.

\begin{tabular}{|c|c|c|c|c|c|c|c|c|c|c|c|c|c|c|c|c|}
\hline \multirow{3}{*}{ Groups } & \multicolumn{15}{|c|}{ Criteria } & \multirow{3}{*}{$\begin{array}{l}\text {-Overall } \\
\text {-Median (*) }\end{array}$} \\
\hline & \multicolumn{5}{|c|}{ Inflammatory cell response } & \multicolumn{6}{|c|}{ Tissue disorganization } & \multicolumn{4}{|c|}{ Tertiary dentin formation } & \\
\hline & 0 & 1 & 2 & 3 & Median & 0 & 1 & 2 & 3 & Median & 0 & 1 & 2 & 3 & Median & \\
\hline Control YT & 4 & 0 & 0 & 0 & 0 & 4 & 0 & 0 & 0 & 0 & 4 & 0 & 0 & 0 & 0 & $0 \mathrm{a}$ \\
\hline Bleached YT & 0 & 3 & 2 & 0 & 1 & 0 & 1 & 4 & 0 & 2 & 0 & 1 & 3 & 1 & 2 & $2 \mathrm{~b}$ \\
\hline Control OT & 4 & 0 & 0 & 0 & 0 & 4 & 0 & 0 & 0 & 0 & 4 & 0 & 0 & 0 & 0 & $0 \mathrm{a}$ \\
\hline Bleached OT & 0 & 3 & 2 & 0 & 1 & 0 & 2 & 3 & 0 & 3 & 0 & 2 & 2 & 1 & 2 & $2 \mathrm{~b}$ \\
\hline
\end{tabular}

$(*)$ Overall medians for each group. Different letters indicate significant differences (Mann-Whitney test, $\mathrm{p}<0.05$ ).

line observed in the sections stained with $\mathrm{H} / \mathrm{E}$ or Masson's Trichrome. The DT values obtained from all human incisors used in this study are shown in Table 3. Significant differences were detected only for the main factor, age $(p=0.001)$. A statistically higher DT was observed in those teeth extracted from older participants.

The scores for every criterion determined by the histological assessment of the specimens according to groups are shown in Table 4 . The teeth from both $\mathrm{C}$ groups showed pulp tissue with normal histological features, characterized by the presence of a continuous odontoblast layer as well as defined cell-free and cell-rich zones. No inflammatory pulp reaction or tissue disorganization was observed (Figs. 1a and 1b).

Two human incisors from the bleached OT group exhibited moderate pulp inflammation and tissue disorganization. One of these teeth $(\mathrm{DT}=2.04 \mu \mathrm{m})$ presented intense deposition of tubular reactionary dentin in the tip of the pulp horn (Figs. 2a and 2b). In another tooth that presented DT of $2.12 \mu \mathrm{m}$, a moderate deposition of reactionary dentin was observed around the coronal and radicular pulp tissue (Figs. 2c and 2d). Partial coronal pulp necrosis occurred in three other bleached incisors.

All five young human incisors from the bleached YT group presented partial necrosis of the coronal pulp tissue, such as observed in three bleached incisors of older patients. The subjacent pulp exhibited discrete to moderate pulp inflammation and tissue disorganization. Three of these teeth showed moderate amounts of tubular dentin below the coagulation necrosis. This tertiary tubular dentin, synthesized and deposited by 


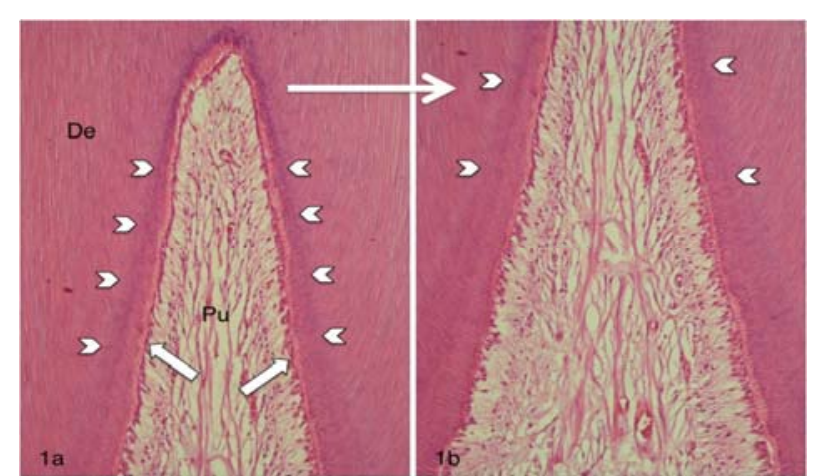

Fig. 1 Control OT. (a) General view of the pulp-dentin complex. A continuous layer of odontoblasts (arrows) is underlying the predentin. Incremental lines characterizing the secondary physiological dentin deposition can be observed (arrowheads). H/E, 48x. (b) Detail of A. Note the cell-free zone, cell-rich zone, and the central core of the pulp tissue. Note the incremental lines in dentin (arrowheads). H/E, 125×. P = Pulp; D = Dentin.

differentiated odontoblast-like cells that were organized in a monolayer (Figs. $3 a$ and $3 b$ ), was continuous with that deposited in the root pulp.

\section{Discussion}

In the present study, all bleached teeth presented pulp tissue alterations characterized by superficial coronal pulp necrosis associated with subjacent inflammatory response and tissue disorganization. No statistically significant differences between the histological features observed for young and old teeth were found. However, tissue necrosis occurred in $60 \%$ of old bleached teeth in comparison with $100 \%$ of young bleached teeth. Additionally, areas of pulp necrosis were larger in older than in young teeth.

One of the most obvious features of aging is the reduction of the pulp chamber area caused by the continuous deposition of physiological collagen-rich dentinal matrix (secondary dentin) by odontoblasts [8, 9]. In the present study, the statistical differences in the DT of young and old teeth indicates that the pathway to the pulp chamber was longer in the latter due to the aging process. Thus, one could expect that this increase in DT, associated with the decrease in permeability because of deposition of peritubular dentin in old teeth, would provide additional pulp protection [10, 11]. However, superficial necrosis was also found in old teeth, which is a cause for concern. The DT increases about $15.5 \%$ in older patients (over 50 years of age) in comparison with young patients (from 10-30 yrs of age); however, this DT variation is accompanied by a $12 \%$ and $30 \%$ decrease in the density of odontoblasts and sub-odontoblasts/fibroblasts, respectively. Additionally, the reduced pulp cell density in old teeth is related to low expression of peroxidades, catalases, and oxygenases [12]. Therefore, the reduced presence of these anti-oxidizing enzymes in old pulps decreases the capability of this specific connective tissue to react against toxic components released from dental products
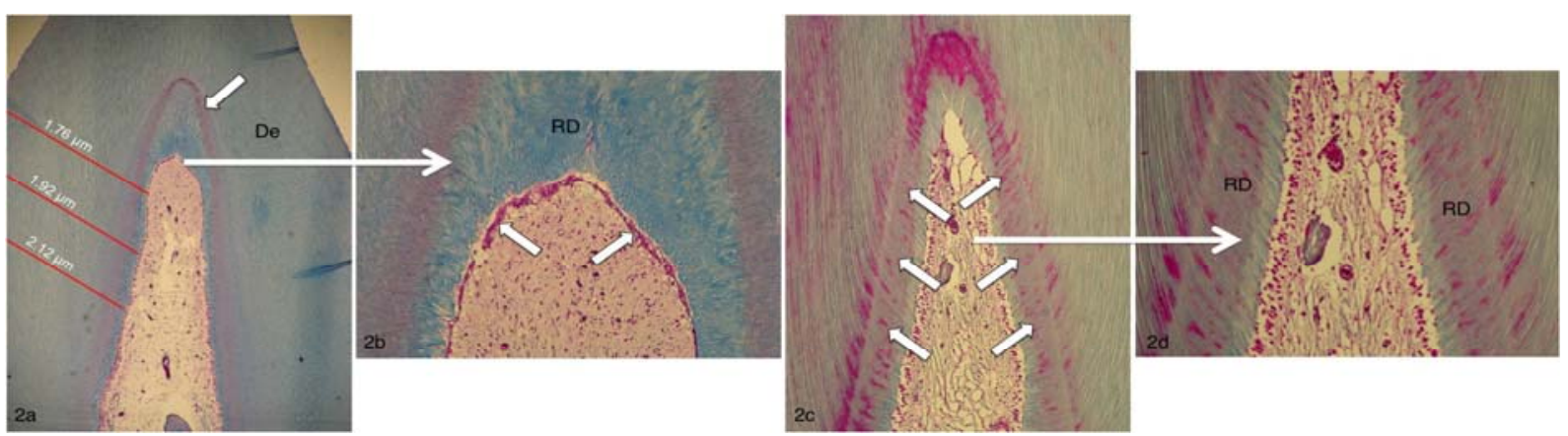

Fig. $235 \%$ HP-OT. (a) Intense deposition of reactionary dentin was observed in the tip of the pulp horn (arrow). In an overview, reactionary dentin was also deposited around the coronal pulp tissue. Note that the DT was measured from the EDJ to the calcium-traumatic line (red). In this specific sample, the DT was $1.93 \mu \mathrm{m}$. Masson's Trichrome, 32×. (b) Detail of A. A continuous odontoblast layer (arrows) is underlying the tubular reactionary dentin. Masson's Trichrome, 250×. P = Pulp; D = Dentin; RD = Reactionary Dentin. This is another example of 35\% HP-OT (2c/d). (c) In this sample, in which the DT was 2.125 $\mu \mathrm{m}$, a moderate deposition of reactionary dentin (arrows) was observed around the coronal pulp tissue. Masson's Trichrome, 48×. (d) Detail of Fig. 3a. Note that the reactionary dentin exhibits fewer tubules than observed in the circumpulpal physiological dentin. Masson's Trichrome, 250x. RD = Reactionary Dentin. 


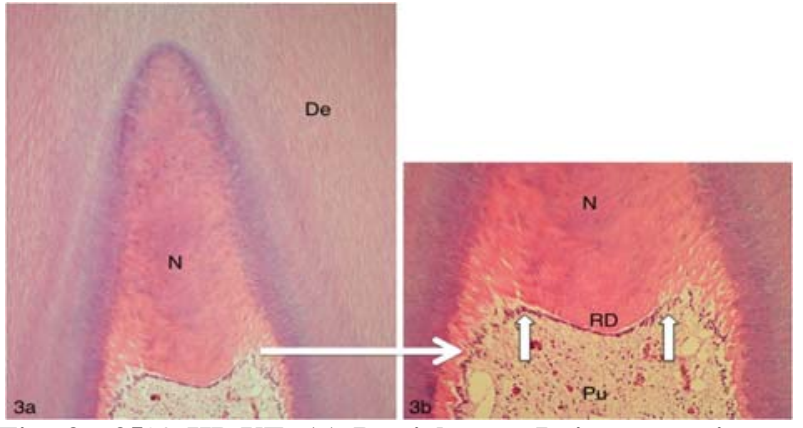

Fig. 3 35\% HP-YT. (a) Partial coaguIation necrosis was observed in the pulp horn $(\mathrm{N})$. Deposition of reactionary dentin was observed below the necrotic tissue as well as around the residual coronal and radicular pulp. H/E, 48×. (b) Detail of Fig. 4a. Note the continuous odontoblast layer (arrows) underlying the tubular reactionary dentin. The subjacent pulp tissue exhibits discrete inflammatory responses mediated by mononuclear cells among a number of small congested blood vessels. H/E, 250 $\times$. P = Pulp; D = Dentin; RD = Reactionary Dentin.

such as bleaching agents. Thus, the likely additional advantage of increased DT may be counteracted by the decreased healing potential of old pulp tissue $[8,9]$.

The pathway related to pulp damage induced by a bleaching agent has been related to HP and the diffusion of its by-products across enamel and dentin to reach the pulp chamber [7]. HP is a kind of reactive oxygen species (ROS) capable of dissociating into other ROS with a high level of oxidative activity, such as peri-hydroxyl ion $\left(\mathrm{HO}_{2}{ }^{-}\right)$, superoxide anion $\left(\mathrm{O}_{2}{ }^{-}\right)$, singlet oxygen $\left(\mathrm{O}^{-2}\right)$, and hydroxyl ion $\left(\mathrm{HO}^{-}\right)$. These molecules play an important role in stress-mediated pulp inflammation $[13,14]$. In vitro studies have shown that the inward enamel/dentin diffusion of bleaching gel components causes intense toxic effects on pulp cells $[15,16]$. When in contact with high levels of ROS, the oxidative stress arises, as the concentrations of ROS exceed the cellular ability to remove highly oxidative molecules and repair cellular damage [17]. Therefore, cell homeostasis is compromised by the accumulation of dysfunctional macromolecules and lipid peroxidation initiation, which can culminate in cell membrane rupture and cell death by necrosis [15, 17]. Also, it was recently demonstrated that the application of a highly concentrated HP bleaching gel to young premolars increased the activity of metalloproteinases and cystein cathepsin B in the pulp tissue [18]. Therefore, the tissue degeneration mediated by these proteases, associated with the release of lysosomal enzymes from necrotic cells, may lead to intense tissue damage [17], as observed in the present study.

Associated with the histological pulp alterations observed in this study, all bleached teeth presented sensitivity. Based upon these data, we suggest that the TS occurring immediately after bleaching in the incisors was a result of the inflammatory reaction mediated by bleaching gel by-products' oxidative damage. Dental pulp is a highly specialized connective tissue almost completely covered by a mineralized tissue, the dentin. Under inflammation, local tissue pressure increases, leading to stimulation of nerve fibers, its spreading and also release of several mediators related to pain [19]. Consequently, teeth become more sensitive, as claimed in the present study by patients who underwent the bleaching procedures [1-4]. Recent clinical investigations have demonstrated that the TS is restricted to anterior teeth after in-office bleaching procedures [1, 2]. According to Bonafé et al. [2], patients subjected to the same bleaching treatment as performed in the present study had TS in $76.6 \%$ of lateral incisors, $53.3 \%$ of central incisors, and $30 \%$ of canines, with no reports in premolars. Thus, one can conclude that enamel/dentin thickness plays an important role in HP penetration of the pulp chamber and its consequent damage to pulp cells.

The data obtained in this study corroborate those of previous investigations $[6,20,21]$. However, superficial zones of coronal pulp necrosis occurred in young human mandibular incisors even after a single clinical session of in-office bleaching [6]. It was also shown that rat molars subjected to the same bleaching protocol as used in the present study presented coronal pulp necrosis associated with intense inflammatory reaction in the radicular pulp tissue. The authors demonstrated that repetition of tooth-bleaching 
sessions resulted in greater pulp necrosis [22].

Despite the superficial coronal necrosis observed in the present study, the subjacent pulp tissue of those bleached teeth still presented healing potential. In both YT and OT groups, the histological sections evidenced a number of differentiated odontoblast-like cells that deposited a layer of tubular reactionary dentin (Figs. 3a and $3 b$ ). Similar pulpal responses have been shown after the application of calcium hydroxide to exposed pulp tissue. In this specific situation, a layer of differentiated odontoblast-like cells can be seen underlying the coagulation pulp necrosis caused by the caustic property of the capping agent [23, 24]. Therefore, it seems that even after the tissue damage caused by the in-office bleaching procedure evaluated in the present study, the pulpal cells subjacent to the necrotic tissue maintained their phenotype, being capable of keeping the homeostasis of the pulp-dentin complex.

Based on the data obtained in this investigation as well as in previous in vivo studies [6, 20-22], new strategies for in-office bleaching therapy should be focused on preventing pulp damage and improving pulp cell regenerative potential. It was recently demonstrated that reducing the contact time of a $35 \%$-HP gel (5-15 min) with enamel led to decreases in about $60 \%$ the transenamel and transdentinal diffusion of HP [26]. A reduction in the HP concentration in bleaching gels (15\%-17.5\%) also decreases the: (1) HP diffusion through enamel and dentin $[15,25]$; (2) pulp cell toxicity [15]; and (3) clinical tooth sensitivity [26]. In addition, mineralization activity is up-regulated when cultured pulp cells are exposed to low concentrations of HP [28-30]. It is known that decreasing the concentration of HP in the bleaching gels or reducing the application time of these products to enamel does not cause an immediate visual (esthetic) impact, as observed in the present study. Conversely, Soares et al. [25] demonstrated that satisfactory tooth color change may be achieved using additional bleaching sessions, with the advantage of reducing the risks of pulpal damage. However, more clinical studies are needed to verify and correlate bleaching effectiveness and pulpal damage using such new tooth-bleaching strategies in anterior teeth.

In this study, it was demonstrated that professional in-office tooth-bleaching therapy using a 35\%-HP gel applied to mandibular human incisors of young and old patients causes pulpal damage, characterized by superficial necrosis of coronal pulp tissue associated with reactionary dentin deposition and inflammatory response. However, the prevalence of superficial necrosis was higher in young teeth. Despite the human clinical tests that have been regarded as the "gold standard" for assessing biological pulp responses to new dental products and techniques [27], we suggest that the data obtained in this study performed in human teeth should be interpreted with caution, because only 5 teeth from young and old patients were used, and the pulp responses were evaluated only two days after the bleaching procedures. Thus, further long-term investigations evaluating pulp sensitivity and human pulp responses after in-office tooth-bleaching therapies should be undertaken.

\section{Conclusions}

According to the methodology used in the present study, it can be concluded that the traditional in-office therapy with a $35 \%$-HP gel applied on lower human incisors of young and old patients causes pulpal damage, characterized by superficial necrosis of coronary pulp tissue associated with reactionary dentin deposition and inflammatory response.

\section{Acknowledgments}

This study was partially supported by the National Council for Scientific and Technological Development [grants number 301937/2009-5, 301891/2010-9, 301291/2010-1] and FUNDUNESP [grant number 0024/021/13-PROPe/CDC].

\section{References}

[1] L.C. Almeida, H. Riehl, P.H. Santos, M.L. Sundfeld, A.L. Briso, Clinical evaluation of the effectiveness of different 
bleaching therapies in vital teeth, Int. J. Period Rest Dent. 32 (3) (2012) 303-309.

[2] E. Bonafé, C.L. Bacovis, S. Iensen, A.D. Loguercio, A. Reis, S. Kossatz, Tooth sensitivity and efficacy of in-office bleaching in restored teeth, J. Dent. 41 (4) (2013) 363-369.

[3] S. Kossatz, A.P. Dalanhol, T. Cunha, A.D. Loguercio, A. Reis, Effect of light activation on tooth sensitivity after in-office bleaching, Oper. Dent. 36 (3) (2011) 251-257.

[4] A. Reis, A.P. Dalanhol, T.S. Cunha, S. Kossatz, A.D. Loguercio, Assessment of tooth sensitivity using a desensitizer before light-activated bleaching, Oper. Dent. 36 (1) (2011) 12-17.

[5] R.H. Leonard, L.R. Smith, G.E. Garland, K.K. Tiwana, L.A. Zaidel, G. Pugh, et al., Evaluation of side effects and patients' perceptions during tooth bleaching, J. Esthet. Rest. Dent. 19 (6) (2007) 355-364.

[6] C.A. de Souza Costa, H. Riehl, J.F. Kina, N.T. Sacono, J. Hebling, Human pulp responses to in-office tooth bleaching, Oral Surg Oral Med. Oral Pathol. Oral Radiol. Endod. 109 (4) (2010) e59-e64.

[7] S.E.A. Camargo, M.C. Valera, C.H.R. Camargo, M.N.G. Mancini, M.M. Menezes, Penetration of $38 \%$ hydrogen peroxide into the pulp chamber in bovine and human teeth submitted to office bleach technique, J. Endod. 33 (9) (2007) 1074-1077.

[8] D.R. Morse, Age-related changes of the dental pulp complex and their relationship to systemic aging, Oral Surg. Oral Med. Oral Pathol. 72 (6) (1991) 721-745.

[9] P.E. Murray, H.R. Stanley, J.B. Matthews, A.J. Sloan, A.J. Smith, Age-related odontometric changes of human teeth. Oral Surg. Oral. Med. Oral Pathol. Oral Radiol. Endod. 93 (5) (2002) 474-482.

[10] I.A. Mjör. Dentin permeability: The basis for understanding pulp reactions and adhesive technology, Braz. Dent. J. 20 (1) (2009) 3-16.

[11] D.H. Pashley, Dentin-predentin complex and its permeability: Physiologic overview, J. Dent. Res. 64 (1985) 613-620.

[12] W.H. Bowles, H.J. Burns, Catalase/peroxidase activity in dental pulp, J. Endod. 18 (11) (1992) 527-534.

[13] S.R.J. Simon, A. Berdal, P.R. Cooper, P.J. Lumley, P.L. Tomson, A.J. Smith, Dentin-pulp complex regeneration: From lab to clinic, Adv. Dent. Res. 23 (3) (2011) 340-345.

[14] T. Zhu, B.S. Lim, H.C. Park, K.M. Son, H.C. Yang, Effects of the iron-chelating agent deferoxamine on triethylene glycol dimethacrylate, 2-hydroxylethyl methacrylate, hydrogen peroxide-induced cytotoxicity, J. Biomed. Mater. Res. B Appl. Biomater. 100 (1) (2012) 197-205.

[15] D.G. Soares, F.G. Basso, J. Hebling, C.A. de Souza Costa, Concentrations of and application protocols for hydrogen peroxide bleaching gels: Effects on pulp cell viability and whitening efficacy, J. Dent. 42 (2) (2014)185-198.

[16] D.G. Soares, A.P. Ribeiro, F. da Silveira Vargas, J.
Hebling, C.A. de Souza Costa, Efficacy and cytotoxicity of a bleaching gel after short application times on dental enamel, Clin. Oral. Invest. 17 (8) (2013) 1901-1909.

[17] T.C. Squier, Oxidative stress and protein aggregation during biological aging, Exp. Gerontol. 36 (9) (2001) 1539-1550.

[18] C. Sato, F.A. Rodrigues, D.M Garcia, C.M. Vidal, D.H. Pashley, L. Tjäderhane, et al., Tooth bleaching increases dentinal protease activity, J. Dent. Res. 92 (2) (2013) 187-192.

[19] D.H. Pashley, How can sensitive dentine become hypersensitive and can it be reversed?, J. Dent. 41 (Suppl 4) (2013) S49-S55.

[20] J. Caviedes-Bucheli, G. Ariza-García, S. Restrepo-Méndez, N. Ríos-Osorio, N. Lombana, H.R. Muñoz, The effect of tooth bleaching on substance $\mathrm{P}$ expression in human dental pulp, J. Endod. 34 (12) (2008) 1462-1465.

[21] J.F. Kina, C. Huck, H. Riehl, T.C. Martinez, N.T. Sacono, A.P. Ribeiro, et al., Response of human pulps after professionally applied vital tooth bleaching, Int. Endod. J. 43 (7) (2010) 572-580.

[22] L.T. Cintra, F. Benetti, A.C. da Silva Facundo, L.L. Ferreira, J.E. Gomes-Filho, E. Ervolino, et al., The number of bleaching sessions influences pulp tissue damage in rat teeth, J. Endod. 39 (12) (2013) 1576-1580.

[23] J. Hebling, E.M. Giro, C.A. Costa, Biocompatibility of an adhesive system applied to exposed human dental pulp, J. Endod. 25 (10) (1999) 676-682.

[24] K.C. Modena, L.C. Casas-Apayco, M.T. Atta, C.A. Costa, J. Hebling, C.R. Sipert, et al., Cytotoxicity and biocompatibility of direct and indirect pulp capping materials, J. Appl. Oral Sci. 17 (6) (2009) 544-554.

[25] D.G. Soares, F.G. Basso, E.C. Pontes, L.R. Garcia, J. Hebling, C.A. de Souza Costa, Effective tooth-bleaching protocols capable of reducing $\mathrm{H}_{2} \mathrm{O}_{2}$ diffusion through enamel and dentine, J. Dent. 42 (3) (2014) 351-358.

[26] M. Ozcan, S. Abdin, C. Sipahi, Bleaching induced tooth sensitivity: Do the existing enamel craze lines increase sensitivity? A clinical study, Odontology. 102 (2) (20143) 197-202.

[27] I.A. Mjör. Minimum requirement for new dental materials, J. Oral Rehabil 34 (2007) 907-912.

[28] D.H. Lee, B.S. Lim, Y.K. Lee, H.C. Yang, Effects of hydrogen peroxide $\left(\mathrm{H}_{2} \mathrm{O}_{2}\right)$ on alkaline phosphatase activity and matrix mineralization of odontoblast and osteoblast cell lines, Cell. Biol. Toxicol. 22 (1) (2006) 39-46.

[29] S. Matsui, C. Takahashi, Y. Tsujimoto, K. Matsushima, Stimulatory effects of low-concentration reactive oxygen species on calcification ability of human dental pulp cells, J. Endod. 35 (1) (2009) 67-72.

[30] K.S. Min, H.J. Lee, S.H. Kim, S.K. Lee, H.R. Kim, H.O. Pae, Hydrogen peroxide induces heme oxygenase-1 and dentin sialophosphoprotein mRNA in human pulp cells, J. Endod. 34 (8) (2008) 983-989. 